\title{
La tradición musical andina en vasos de madera incas
}

\author{
Cruz Martínez de la Torre *
}

Perú, país de variados paisajes y acentuados contrastes climáticos y culturales constituye el escenario donde florece entre los siglos $x V$ y $x V I$ la cultura inca, último eslabón de la tradición artística prehispánica de los Andes Centrales. A nivel histórico el pueblo inca pasó, en poco menos de una centuria, de ser un pequeño señorío local, con una experiencia cultural modesta, al gran estado que los españoles hallaron al llegar a estas tierras, combinándose en él su propia idiosincrasia con la dilatada y brillante tradición cultural del mundo andino. El resultado de dicha fusión es la aparición de un estilo característico y bien definido al que, con posterioridad al año 1533, se sumará la tradición cultural europea, combinándose los caracteres propios de ambos mundos. Con la llegada de los nuevos colonizadores se configura una primera etapa en la que el imperio inca se derrumba ante el aún débil poder europeo, sin que ésto suponga su desaparición cultural. Este hecho se manifiesta en la persistencia de elementos plásticos del incario en los lienzos coloniales, en los dibujos del historiador Guamán Poma de Ayala ${ }^{1}$ (fig. 1) y en otras manifestaciones artísticas donde las señas de identidad andina conviven con la nueva iconografía de origen europeo. Entre éstas últimas destacan, por su notoriedad, los keros y las pajchas - vasos ceremoniales de forma troncocónica y recipientes para libaciones con forma de gran pipa, respectivamenteobjetos de culto específicos del arte inca, realizados en madera, que fueron utilizados en distintos rituales por el Inca y la élite gobernante ${ }^{2}$.

Dpto. H. ${ }^{a}$ del Arte. UNED.

Guaman Poma de Ayala, F. 1980 (1613), Nueva crónica y buen gobierno. México, Siglo xXı.

El Museo de América de Madrid posee una de las más valiosas colecciones al respecto con setenta keros y seis pajchas. 


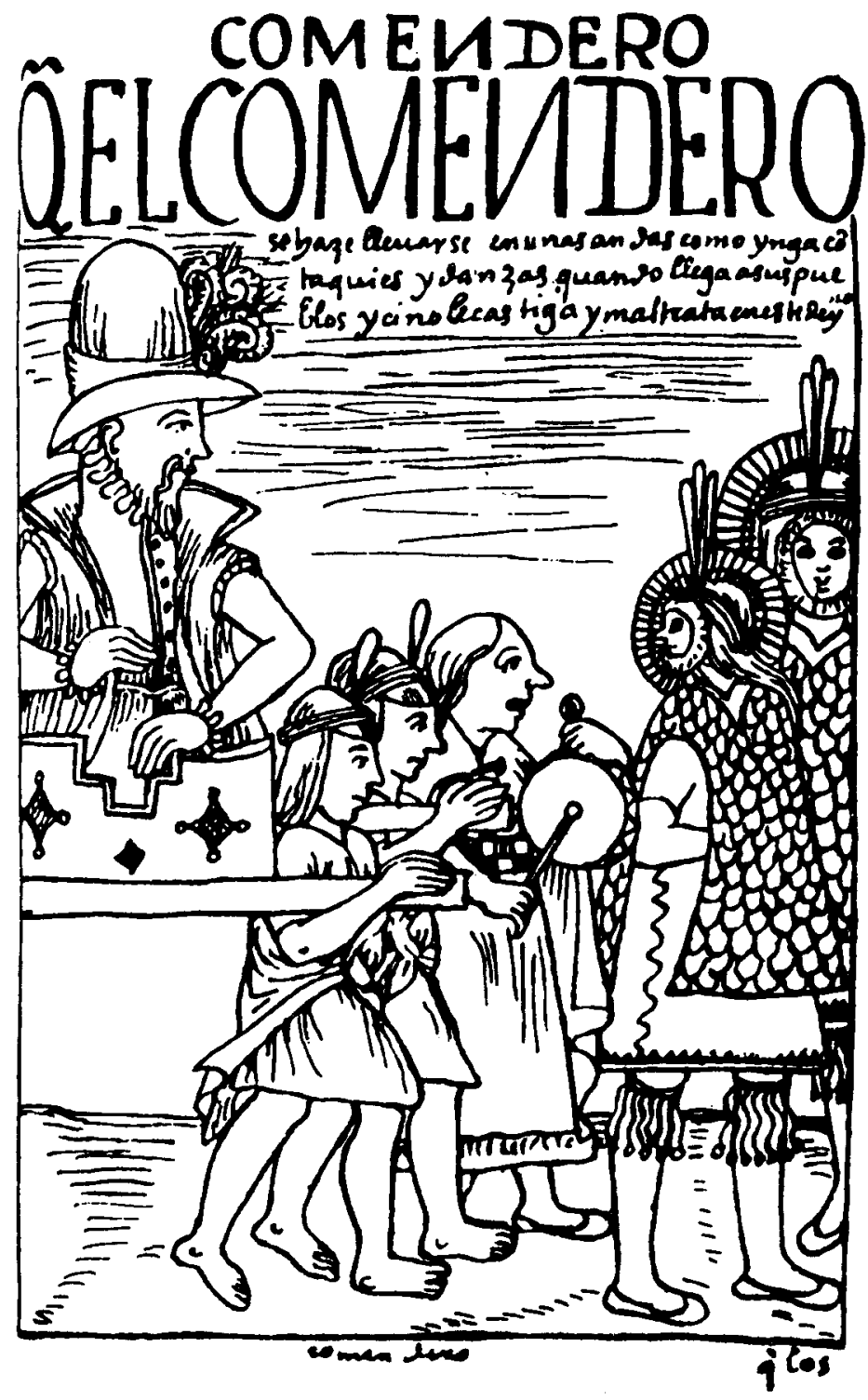

Fig. 1. 554 Comendero. Guamán Poma de Ayala 
La sustitución tras la conquista española del oro y de la plata por la madera en la fabricación de estos vasos determinó que la policromía pasara a considerarse un nuevo parámetro de riqueza, desarrollándose en ellos una exquisita decoración de raíz indígena aun cuando la mayor parte de los que actualmente se conservan fueron fabricados con posterioridad a la llegada de los españoles a estas tierras ${ }^{3}$. Su decoración, sujeta siempre a la ley del marco, suele concentrarse en tres bandas: la superior, generalmente más ancha, donde se sitúa el tema principal en una escena continua, la central con diseños geométricos, y la inferior con motivos fitomorfos o zoomorfos. Obviamente este esquema presenta variaciones que suelen ser más frecuentes en vasos de fabricación tardia ${ }^{4}$, pudiendo transformarse dichos espacios decorativos en dos frisos o, incluso, convertirse en una única superficie ornamental. Las técnicas utilizadas para la realización de dichas escenas son, conforme a su antigüedad, la incisión, la pintura sin incrustar y la laca incrustada, esta última utilizada masivamente a partir de la Conquista.

Entre el amplio repertorio temático sobresalen las escenas ceremoniales, las tomadas de la tradición histórica incaica y los diseños florales y heráldicos, temas en los que el folklore musical suele reflejarse ampliamente dada la importancia que desde la antigüedad tuvieron en todas las culturas prehispánicas la música y la danza, artes estrechamente vinculadas al ritual ${ }^{5}$. Pese a la amplitud de conocimientos musicales que tu-

3 Dicha iconografía constituye un elemento determinante a la hora de poder datar estas obras. Así, en el momento previo al contacto de ambas culturas y en los primeros años del mismo predomina la decoración formada por sencillos motivos geométricos incisos, sin que haya motivos figurativos antropomorfos ni fitomorfos, siendo a finales del siglo xvi cuando la figura humana aparece en composiciones de temática muy diversa. Al respecto consúltese, entre otras, las obras de RowE, J.H. 1961, "The cronology of Inca Wooden Cups", Essays in Pre Columbian Art and Archaeology, págs. 317-341. Cambridge, Harvard University Press, y 1982, "La cronología de los vasos de madera inca", Arqueología del Cuzco; Cuzco, Ed. del Instituto Nacional del Cultura de Cuzco; MARTínez C. y CABELLO, P. 1988, “El arte inca epigonal», Piedras y oro. El arte en el imperio de los Incas. Alicante, Museo de América, Ministerio de Cultura, Caja de Ahorros del Mediterráneo; ALONSo, A. 1990, "El kero: vaso ritual de los incas", Espacio, Tiempo y Forma, págs. 11-30, Madrid; LieBSCHER, V. 1986, La iconografia de los keros. Lima, Herrero Editores.

4 Es decir, de los siglos xVIII y xIx. Rowe localizó un kero en el Museo de la Cultura Peruana de Lima datable en 1821-1822.

5 Este hecho puede constatarse en las obras de numerosos cronistas, entre los que citaremos, para el área andina a COBO, B. 1956 (1653), Historia del Nuevo Mundo, Biblioteca de Autores Españoles. Madrid, Ed. Atlas; CIEZA DE LEÓN, P. de 1967 (1550), El Señorío de los Incas. Lima, Instituto de Estudios Peruanos MoLINA, C. 1944 (1571), "Fábulas y ritos de los Incas", Las crónicas de los Molinas. Lima, Ed. Domingo Miranda, págs. 7-84; Guamán Poma de AyalA, F. 1987 (1615), Nueva crónica y buen gobierno. Madrid, Ed. Historia 16; Guamán Poma de Ayala, F. 1943 (1609), Comentarios Reales de los Incas. Buenos Aires, Emecé Editores. 
vieron todos estos pueblos ninguno llegó a poseer un sistema de notación, de forma que fue la tradición oral la encargada de transmitir sus reglas específicas. Ésto dificulta la verificación de cualquier conclusión a la que hoy pueda llegarse al respecto, restando tan solo para su fundamentación los escasos restos arqueológicos de su instrumental, los datos de los cronistas, las representaciones artísticas y las reminiscencias musicales rastreables en el actual folkore indígena ${ }^{6}$. Pese a la mencionada carencia de noticias específicas sobre su aspecto rítmico, estructural o melódico, los musicólogos suponen que la primitiva música americana debió de haber sido monódica, acompañándose con posterioridad de instrumentos de percusión que reforzarán su ritmo. La persistente reiteración de un mismo sonido o de motivos rítmicos y la preponderancia de la escala pentatónica parecen haber sido, pues, algunas de sus características principales, si bien existió además en el área andina y mesoamericana otra escala con semitonos, utilizada en menor medida ${ }^{7}$. La ejecución del instrumental estuvo vinculada al canto y ambos, casi siempre, a la danza. Ésta tuvo un doble carácter, ceremonial y profano, constituyendo una forma de expresión colectiva de carácter religioso y social. Cobo ${ }^{8}$ señala que «Casi no tenían baile que no lo hiciesen cantando, y así el nombre de taqui, que quiere decir baile, lo significa todo junto, baile y cantar; $y$ cuantas eran las diferencias de cantares, tantas eran las de bailes". A esta diversidad se añadía el que cada una de las regiones que componían el imperio poseía su música, sus cantares y sus bailes propios, así como sus vestidos y adornos particulares que no podían cambiar, a través de los cuales se reconocía a cada nación ${ }^{9}$. Por norma general las danzas

6 Cabello P. y Martinez C. 1988, Música y arqueología en América Precolombina. Oxford, BAR Internacional Series 450 , con amplia bibliografía al respecto.

7 D'HARCOURT, Raoul y Marguerite 1925, Les musiques des Incas et ses survivances. Paris, Librairie Orientaliste Paul Geuthner, sostienen la exclusiva existencia de un sistema pentatónico entre los incas. Sin embargo, MEAD, Ch. (1924), en "The musical instruments of the Incas", Anthropological Papers of the American Museum of Natural History, XV, part III. New Yorh, contradice esta teoría tras el estudio de flautas de Pan con sernitonos pertenecientes a la cultura nazca. SAS, C. 1947, en Historia universal de los instrumentos musicales. Buenos Aires, Ed. Centurión, indica que, además del sistema pentatónico, los nazcas utilizaron un sistema diatónico lleno de fórmulas cromáticas empleando, además, intervalos menores o superiores al semitono y otro tipo de intervalos no medibles mediante tonos y semitonos. BAUMAN, M. 1980, en Música andina de Bolivia. Cochabamba, Centro Portales y Laura y Cía; STEVENSON, R. 1968, Music in Aztec and Inca Territory. Berqueley and Los Angeles University of California Press; y VEGA, C. 1934, "Escalas con semitonos en la música de los antiguos peruanos", XXV Congreso Internacional de Americanistas, T.I. Buenos Aires, suscriben también esta teoría.

8 Сово, B., op. cit., Lib. XIV, Cap. XVIII, pág. 270.

9 JIMÉnez BORJA, A. 1946, "La danza en el antiguo Perú (Epóca Inca)», Revista del Museo Nacional. Lima, pág. 122. GarCILASO de LA VEGA, I., op. cit., Lib. IX, Cap. I, pág. 218, indica que "Es de saber que todas las provincias del Perú, cada una de por sí, tenía manera de bailar diferente de las otras, en la cual se conocía cada nación, también como en los diferentes to- 
se interpretaban al aire libre en las plazas y calles y eran ejecutadas en su mayoría por hombres, si bien existieron danzas mixtas y, excepcionalmente, algunas realizadas sólo por mujeres. El número de participantes solía ser alto, bailando sueltos o asidos de las manos o brazos, según fuera la modalidad de danza y el pueblo que la ejecutara ${ }^{10}$ (fig. 2). En cuanto a la temática existieron unas de tipo realista - cuyos movimientos reproducían fielmente el acontecimiento a conmemorar-y otras de carácter más abstracto - en las que no se aludía a hechos de la vida real o de la naturaleza - y cuya interpretación, en ocasiones, era privativa de la nobleza ${ }^{11}$ (fig. 3).

Desde el punto de vista artístico las escenas musicales contenidas en algunos de los keros y pajchas que posee el Museo de América de Madrid se hallan vinculadas a los acontecimientos históricos y a los rituales específicos de la religión inca, estos últimos ostensibles en las celebraciones de su ciclo calendárico. En todas ellas se exhiben diversas danzas así como instrumentos pertenecientes al grupo de los aerófonos, membráfonos, idiófonos y cordófonos, estos últimos introducidos en el Perú tras la Conquista ${ }^{12}$.

Así en el kero n. ${ }^{\circ} 7523$ (fig. 4) puede contemplarse una escena ceremonial relacionada con la agricultura. En ella, y actuando como eje de la composición, el Sol, dueño de la vida vegetal y animal, preside un ritual que se efectúa al pie de las montañas en el que participan dos grupos afrontados de hombres y mujeres, ricamente ataviados, portando en las manos keros con los que realizan una ofrenda a dicha divinidad. En primer plano, junto a cada uno de los ríos que parten del lago situado al pie de las montañas, dos hombres labran la tierra mientras que, al fondo de la escena, otros dos tañen grandes pututos, o caracolas marinas ${ }^{13}$, al tiempo

cados que traian en las cabeças, y estos vailes eran perpetuos, que nunca los trocaban por otros", dato corroborado por otros cronistas.

10 Garcilaso de la Vega, I., op. cit., T. II, Lib. IX, Cap. I pág. 218, relata que «Los Incas tenían un bailar grave y honesto, sin dar brincos ni saltos ni otras mudanças, como los demás hazían». JIMÉNEZ BORJA, A., op. cit., págs. 127-130, analiza la relación con la danza que tuvieron los reyes incas, señalando también que, en general, las señoras princesas fueron muy aficionadas a las mismas.

" JiMÉnez BorJA, A., op. cit., pág. 126.

12 A excepción del arco musical, el único cordófono americano que podría formar parte del antiguo acervo cultural, si bien no existe una certeza total al respecto, según JIMÉNEZ BORJA, $A$. 1951, "Instrumentos musicales peruanos", Revista del Museo Nacional, T. XIX y XX, pág. 46. Lima.

13 El hecho de que la caracola provenga de un animal acuático confiere a este instrumento el poder mágico de atraer la lluvia - según $\mathrm{SACH}_{\mathrm{A}} \mathrm{C}$. 1947, Historia de los instrumentos musicales. Buenos Aires, Ed. Centurión, por lo que la encontramos en este vaso asociada a los ritos de propiciación de las buenas cosechas, si bien en otro aparece asociada a escenas de guerra debido a su potente, hosco y amenzador sonido. 


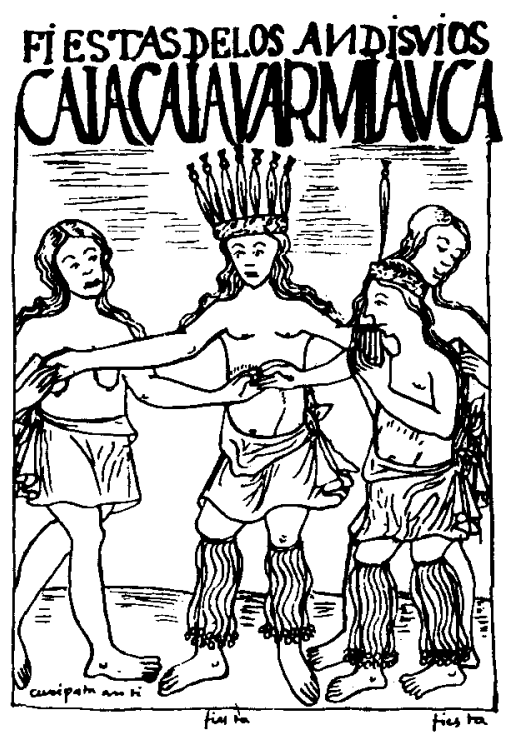

Fig. 2. 322. Fiesta de los Ande Suyos.

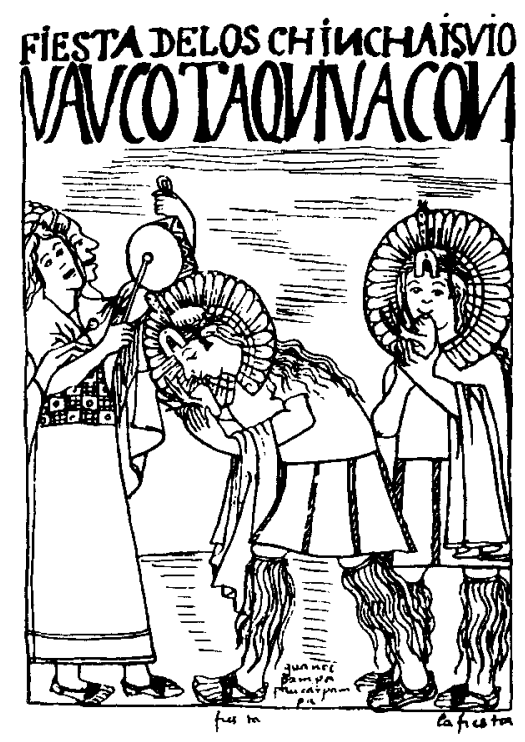

320. Fiesta de los Chinchay Suyos. Guamán Poma de Ayala 


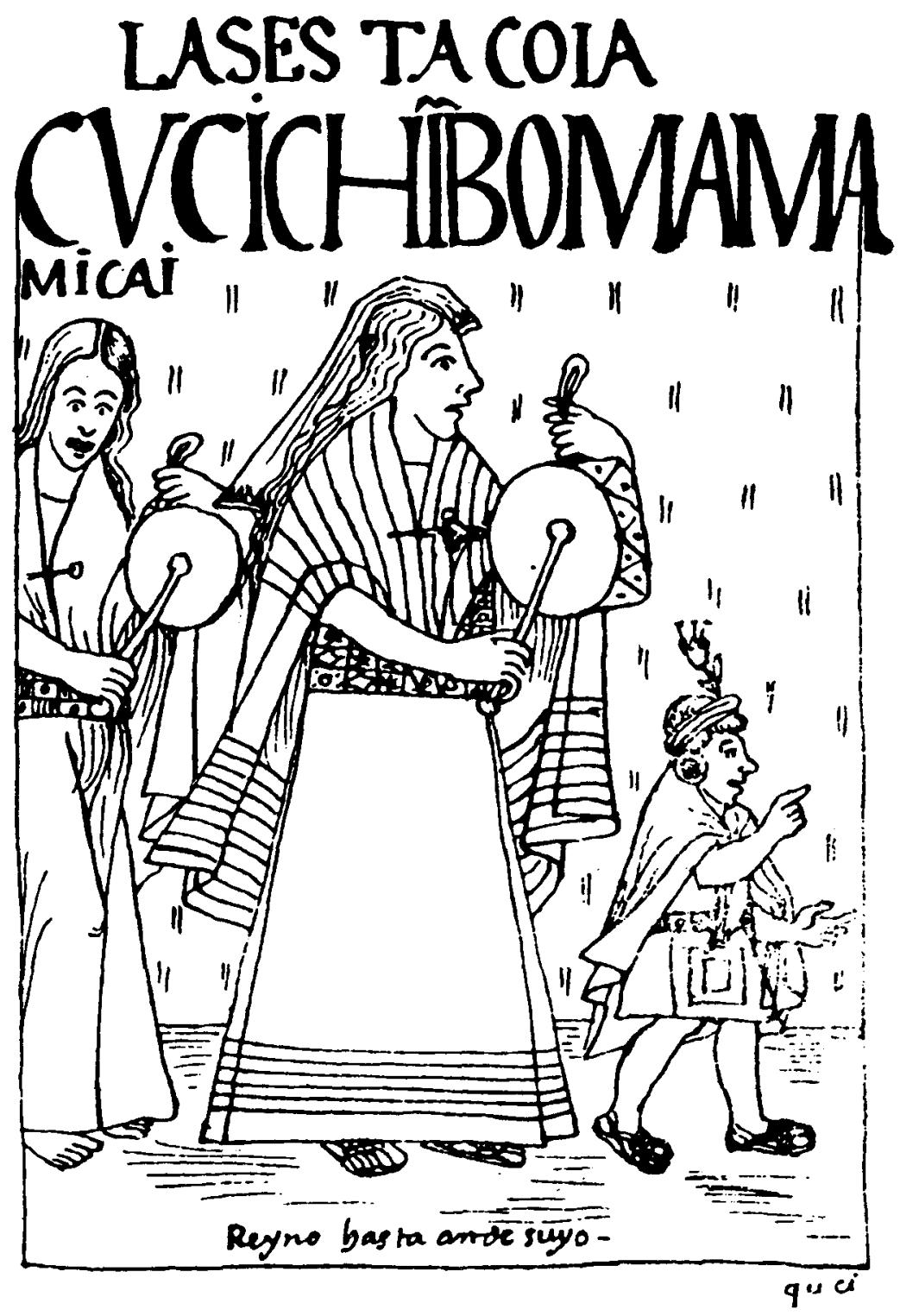

Fig. 3. 130. La Sesta Coia. Cuci Chinbo Mama Micay. Guamán Poma de Ayala 

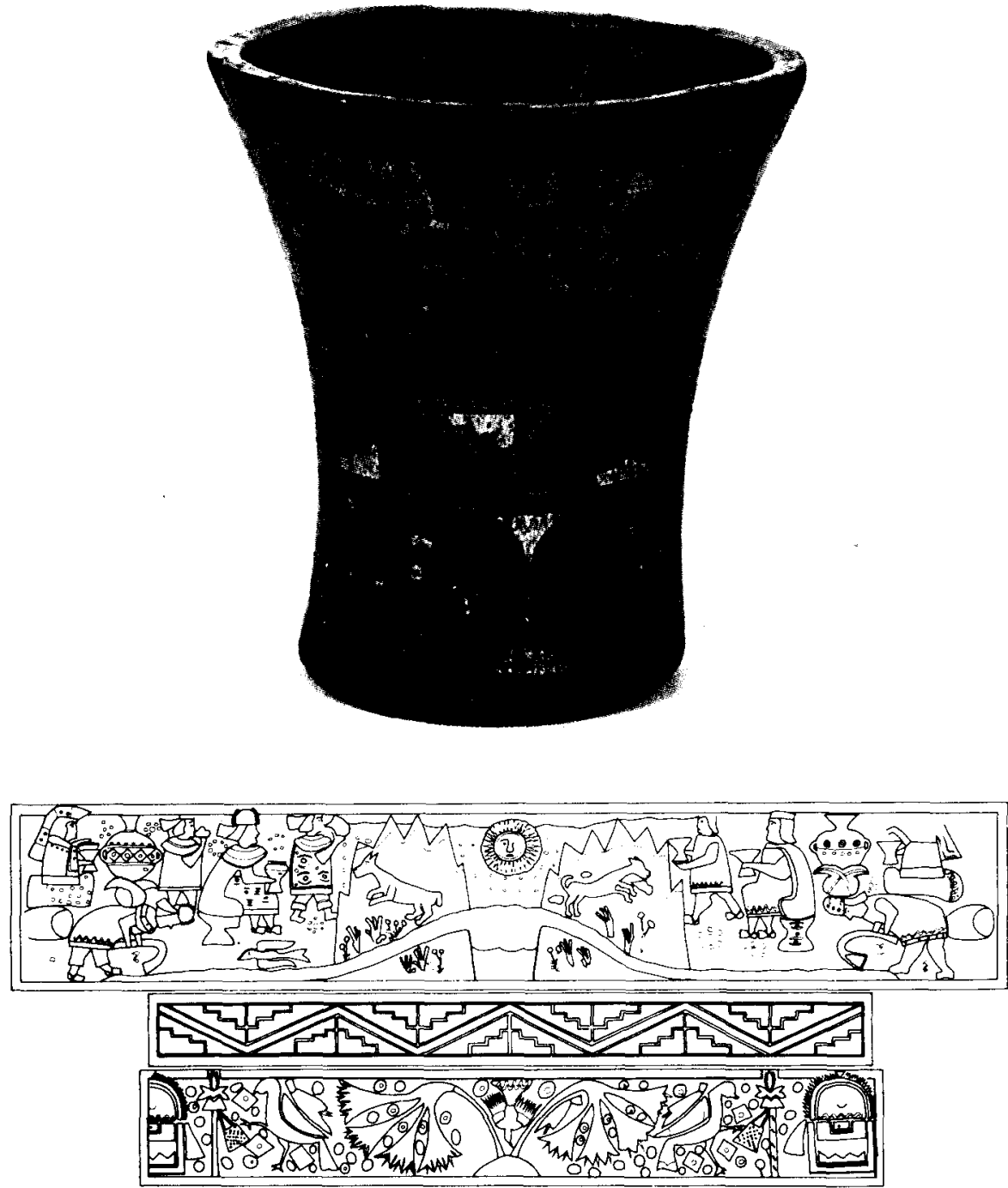

Fig. 4. Kero n..$^{\circ}$ 7523. Desarrollo decorativo del Kero n. ${ }^{\circ} 7523$ M.A.M. 
que danzan. Esta representación podría hacer referencia a una de las cuatro fiestas solemnes que los incas celebraban al año, la del CusquieRaimi ${ }^{14}$, en la que se pedía por la prosperidad de las cosechas. Quizá podría también aludir a la festividad del Capac-Raimi que, entendida como rito agrario, debió estar ligada al crecimiento del maíz, el más insigne cereal que los nobles incas plantaban, cuidaban y cosechaban ceremonialmente ${ }^{15}$ (fig. 5).

La escena incluída en el kero n. 7554 (fig. 6), de factura más tardía que el anterior, podría quizá relacionarse con la permanencia de los antiguos ritos agrarios incas en la fiesta cristiana de la Invención de la Cruz, conocida y celebrada en todos los Andes con el nombre de las Cruces ${ }^{16}$, donde el ceremonial prehispánico del culto a la Pachamama, o Madre Tierra, que tiene lugar al finalizar la cosecha, se funde con la idea cristiana de la adoración de la Cruz. La presencia del tamboril, tocado por una mujer ${ }^{17}$, y la participación de varias figuras masculinas en lo que podría ser una danza, en torno a una aparente res con las patas atadas, evidencia la importancia que la música siguió teniendo en el ritual andino tras la Conquista, importancia que se mantiene hasta nuestros días.

Especialmente interesante dentro de dicho contexto de propiciación del mundo doméstico ${ }^{18}$ resulta la representación contenida en el kero

14 Molina, C., op. cit., págs. 66-67 alude al mes de la cosecha en los siguientes términos: «Al mes de Abril llamaban Ayri-guay cojían las chacras en él, y también las encerraban y recogian, a lo cual llamaban aymoray; y los que habían armado caballeros, salían a la chacra de sausiro a traer el maíz que en ella se había cogido... traíanlo en unos costales pequeños, con un cantar llamado arauí, con unos vestidos galanos; y andaban a traer dicho maíz toda la demás gente del Cuzco, excepto el primer día que lo traían los mozos armados caballeros".

15 Hocouemghem, A.M. 1987, Iconografía mochica, Pontificia Universidad Católica del Perú, San Miguel, Perú, págs. 117-118, analiza esta ceremonia en su doble vertiente, como rito agrario y como rito de pasaje, relacionándola con la iniciación que de los jóvenes nobles tenía lugar en los combates del Camay y vinculando el crecimiento del maiz con la prueba de fuerza y de valor de los jóvenes guerreros. En este contexto se trataria, para la autora, de una ceremonia de propiciación del mundo doméstico, mientras que en el contexto de la primera festividad estaria relacionada con los últimos ritos de duelo y las celebraciones del culto a los ancestros que permiten aprovechar su legado, la cosecha.

16 Al respecto véase SchWAB, F. 1943, "La fiesta de las Cruces y su relación con los antiguos ritos agrícolas", Historia, vol. 1, n. ${ }^{\circ}$, págs. 363-384; y BaUmann, M.P. 1980, Música andina de Bolivia. Cochabamba, Centro Portales y Lauro y CIA.

17 El modelo de tambor representado en estas escenas corresponde al tipo de membráfono de golpe directo, en forma de caja con doble membrana y asa - según la clasificación que de estos instrumentos hace HornBOSTEL, E.M. y SASCH, C. 1961, "Classification of Musical Instruments", The Galpin Society Journal. An occasional publication, n. ${ }^{\circ}$ XIV, págs. 17-20, London, conocido popularmente con los nombres de tamboril, huancar o tinya y que tanto en los keros como en la citada obra de Guamán Poma de Ayala siempre es tañido por mujeres.

18 Hocouemghuem, A.M., op. cit., págs. 122-123. 


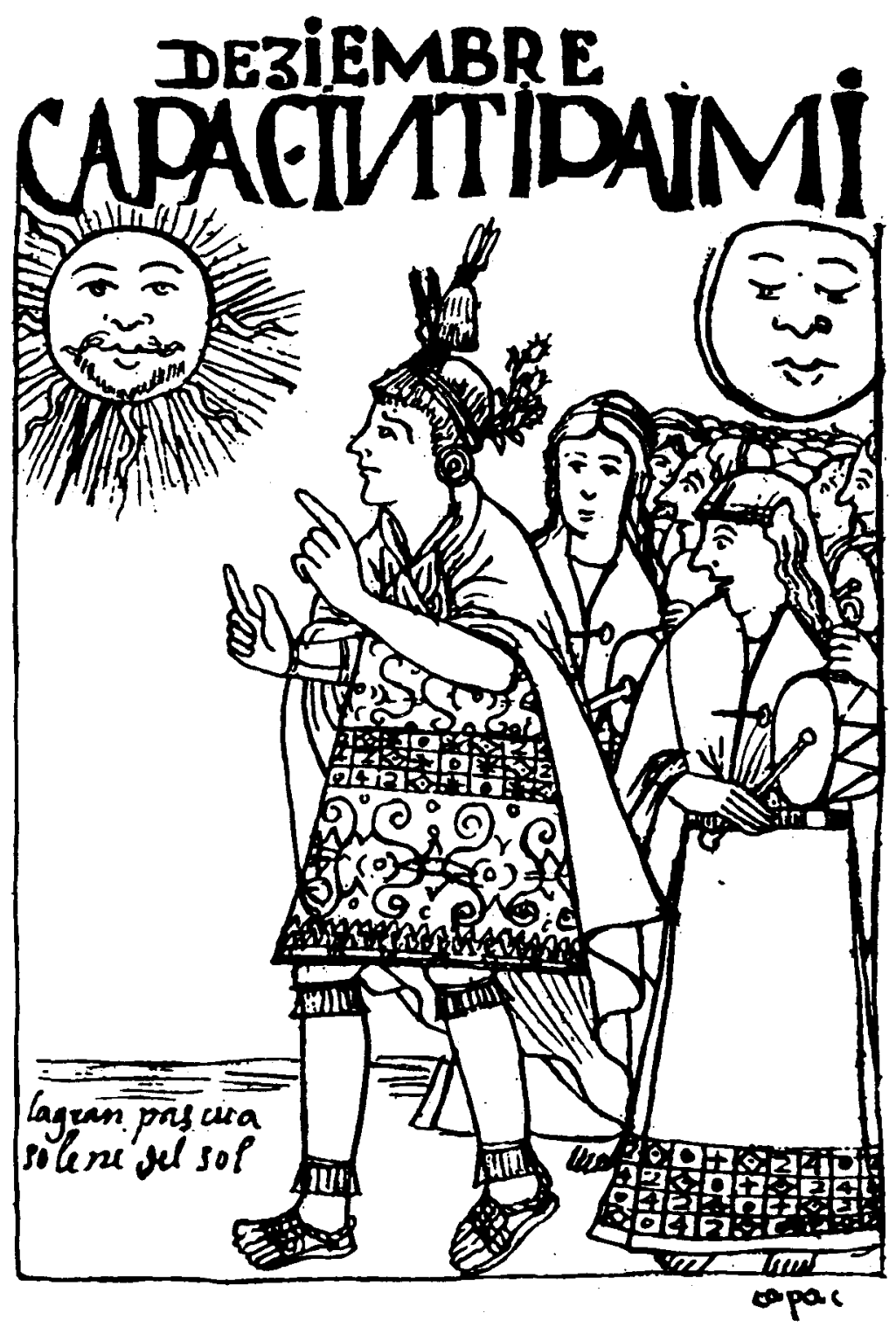

Fig. 5. 258. Deziembre. Capac Inti Raimi. Guamán Poma de Ayala 

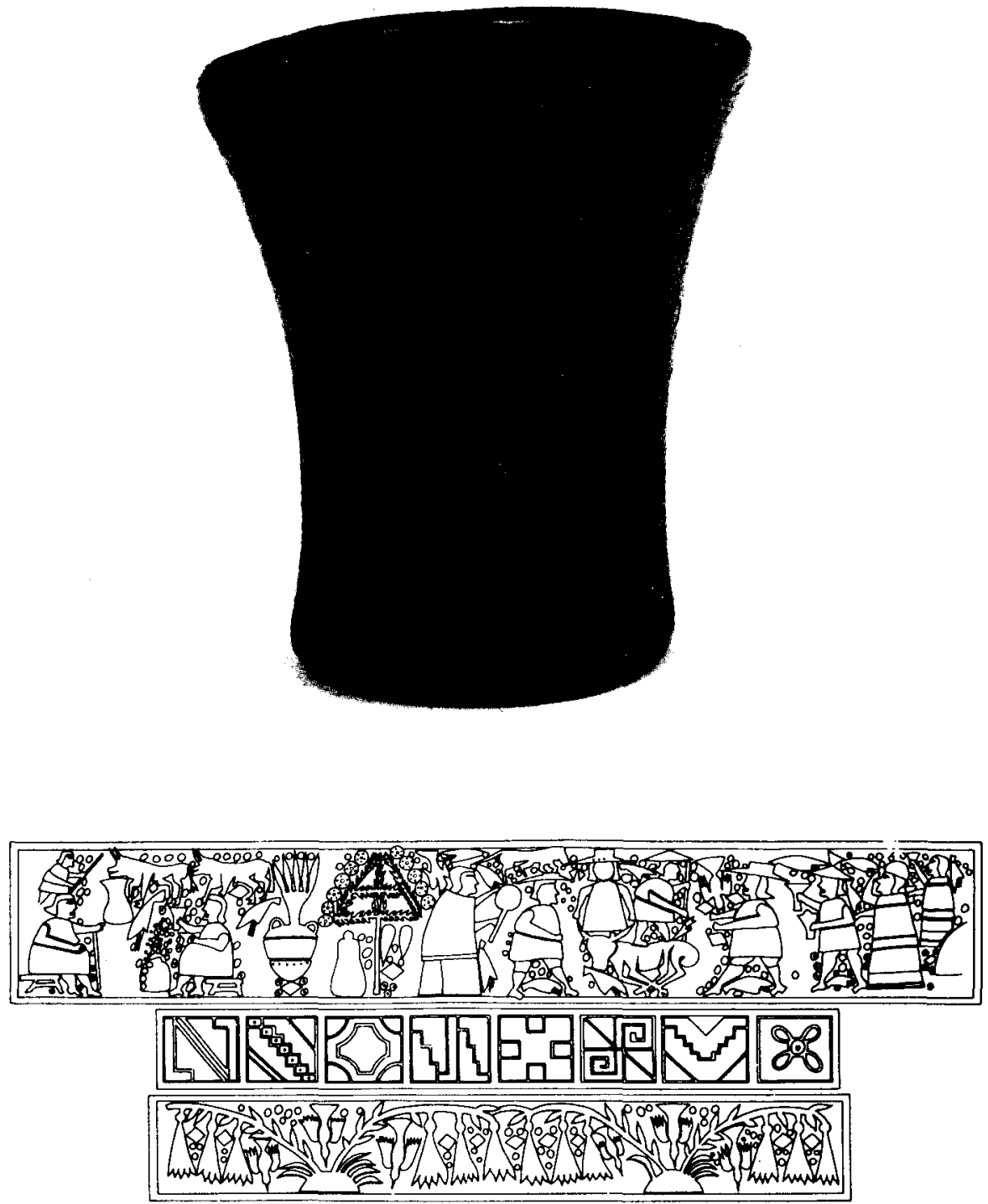

Fig. 6. Kero $n .{ }^{\circ}$ 7554. Desarrollo decorativo del Kero n. ${ }^{\circ} 7554$ M.A.M. 

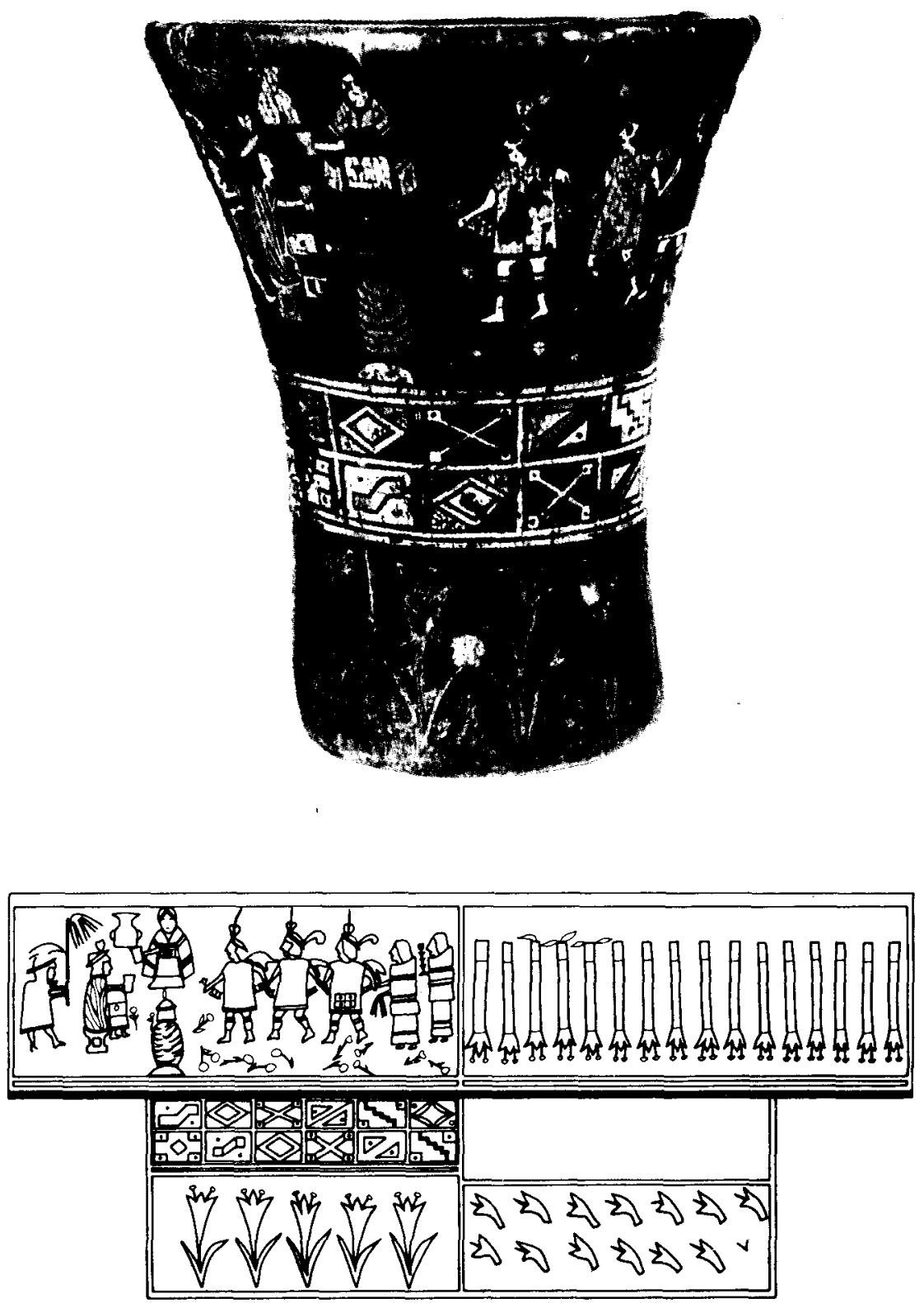

Fig. 7. Kero n. ${ }^{\circ}$ 7524. Desarrollo decorativo del Kero n. ${ }^{\circ} 7524$ M.A.M. 
n. 7524 (fig. 7) donde tres figuras masculinas, con sonajas atadas a las piernas y una supuesta soga o cadena en la mano, danzan ante el Inca y la Coya, la reina, quienes aparecen en la escena con un kero de plata en la mano y ante la momia de un Inca sentado ${ }^{19}$. El historiador Molina ${ }^{20}$ relata cómo los guerreros incas al terminar el combate del Camay bailaban con una gran soga, empezando el canto y hacian el "baile y taqui llamado yauayra, por todas las calles y cuadras del Cuzco, desde que anochecía hasta que amanecía; y a la mañana sacaban los que a cargo tenían las huacas del Hacedor, Sol, Trueno, Luna y los cuerpos muertos a la plaza, donde los ponían en sus lugares; y el Inca salía a ponerse en el suyo, porque era junto al Sol». A este baile se unía el resto de la gente del lugar asida a una soga muy larga, hecha de cuatro colores, "los hombres a una parte y las mujeres a otra, haciendo el taqui llamado yanayra; y allegados a la plaza los delanteros, asidos siempre a la misma guasca, llegaban a hacer reverencia a las huacas, y luego al Inca". Tanto Molina como Cobo ${ }^{21}$ encuadran a esta danza dentro de las celebraciones que tenían lugar con motivo de los festejos del segundo mes -llamado Camay-Quilla, o mes de diciembre-, la cual se ejecutaba para propiciar las buenas cosechas y que, según Hocquenghem ${ }^{22}$, tenía lugar durante el segundo mes de la estación húmeda y caliente, cuando la abundancia de agua permitía la irrigación de las chacras, o tierras de cultivo. Sin embargo, Liebscher ${ }^{23}$ considera que esta escena refleja una danza de origen cortesano interpretada ante un Inca sentado. Dicha danza se ejecutaba con una cadena de oro, si bien parece ser que en realidad se trató de una soga guarnecida con oro a la que se agarraban los danzantes, la cual fue elaborada por orden del Inca Huayna Capac en honor de su hijo y heredero Huáscar.

Un segundo bloque de representaciones es aquel en el que la música forma parte de las secuencias de combates bélicos y de las fiestas $y$ ceremonias desarrolladas en torno a las victorias y a las alianzas militares entre los incas y otras naciones. Tambores, caracolas marinas o pututos, flautas, trompetas y conchas eran los instrumentos tañidos durante la lucha, a los que se sumaba la voz de los guerreros para producir gran

19 Sobre el significado de esta última figura véase Alonso A. 1989, "Las momias de los Incas: su función y realidad social», Revista Española de Antropologia Americana, $n .{ }^{\circ} \mathrm{XIX}$, págs. 123, Madrid.

${ }_{20}$ Molina, C. de, op. cit, pág. 62.

${ }^{21}$ Сово, B., op. cit., Lib. XIII, Cap. XXVI, pág. 213, quien denomina a este baile yaguayra

22 Hocouemguem, A.M., op. cit., pág. 123.

${ }^{23}$ Liebscher, V., op. cit., pág. 56. 
estruendo y aterrorizar al enemigo ${ }^{24}$. Las escenas que con esta temática se desarrollan en los keros n. 7521 y 7511 en la pajcha n. 7570 (fig. 8, 9 y 10) muestran escenas de combate entre el ejército inca y el de los pueblos selváticos que vivían al este del Cuzco, en la región del Antisuyu. En ellos se aprecia el enfrentamiento entre ambos grupos, ataviados cada uno con su atuendo y su armamento característico, en medio de un entorno geográfico en el que se mezclan motivos arquitectónicos incas con temas zoomorfos y fitomorfos privativos de la selva ${ }^{25}$. Pututos, trompetas y tambores, estos últimos tocados por mujeres y por jorobados ${ }^{26}$, son los instrumentos que aparecen en estas piezas, la última de las cuales parece de factura más tardía. Desde el punto de vista del significado Hocquenguem ${ }^{27}$ considera también este tipo de escenas guerreras como propiciatorias del mundo doméstico ya que en los combates los guerreros luchan por el bienestar de toda la comunidad y, según sea el resultado en ellos obtenido, éstos piensan que es posible predecir si la cosecha va a ser o no abundante. En este sentido, es posible que en algunas de las escenas representadas en estos keros se aluda más a combates rituales entre las facciones en liza que a batallas concretas acontecidas entre ambos bandos.

El sometimiento de los pueblos conquistados por los guerreros incas se conmemoraba con largas fiestas que se solemnizaban con cantos y danzas, acordes con el acontecimiento. Tal es el caso de la escena representada en el kero n. 7561 (fig. 11) en la que personajes que portan arcos y flechas bailan, al son de dos arpas, con otros ataviados con pieles de posibles felinos, patentizando así el viejo sentimiento de admiración y respeto que los pueblos andinos tuvieron desde la antigüedad por sus animales totémicos ${ }^{28}$. El hecho de que algunas naciones se preciaran de descender de determinados animales confería a estas danzas un carácter de inequívoca trascendencia, al tiempo que sus peculiares vestimentas aportaban solemnidad y colorido a las fiestas ${ }^{29}$. La presente escena po-

24 Bolaños, C. 1985, "Música y danzas en el antiguo Perú», La música en el Perú, Patronato Popular y Porvenir Pro Música Clásica, pág. 53, Lima.

25 Kauffmann Doig, F. 1978, Manual de arqueología peruana. Lima, ed. Peisa, pág. 754, alude a la dinastía de los soberanos incas que, tras la sublevación de Manco Inca, o Manco II, en 1536, se refugian en el área montañosa de Vilcabamba, siendo los habitantes de esta zona - Ios chunchos o selváticos - incomprensibles y hostiles a los miembros de la dinastia IncaColonial de Vilcabamba, que se extinguió en 1572, lo que se refleja insistentemente en los keros de este período colonial temprano, incluyendo el desarrollo del kero $n{ }^{\circ} 7511$ en dicha publicación.

${ }^{26}$ Bailarines de oficio que acompañaban al ejército en las incursiones bélicas

27 Hocquemguem, A.M., op. cit., pág. 119.

28 Badaracco, A. 1940, "La fauna regional en el totemismo de los antiguos peruanos", $R e-$ vista del Museo Nacional, T. IX, n. ${ }^{\circ}$, págs.13-22, Lima.

29 JiMÉnEZ BORJA, A., op. cit., pág. 145. 

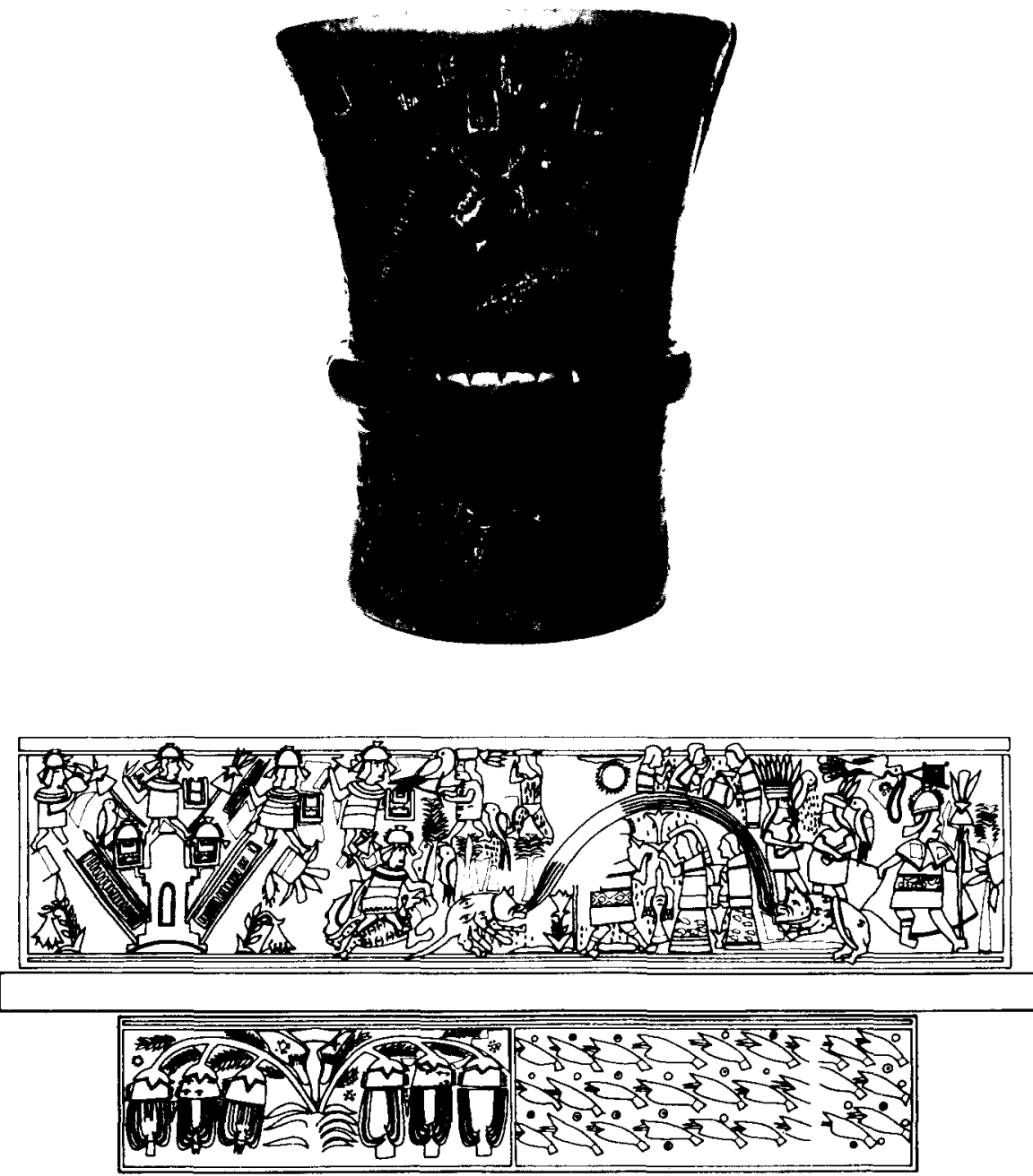

Fig. 8. Kero n. ${ }^{\circ} 7521$. Desarrollo decorativo del Kero n. ${ }^{\circ} 7521$ M.A.M. 

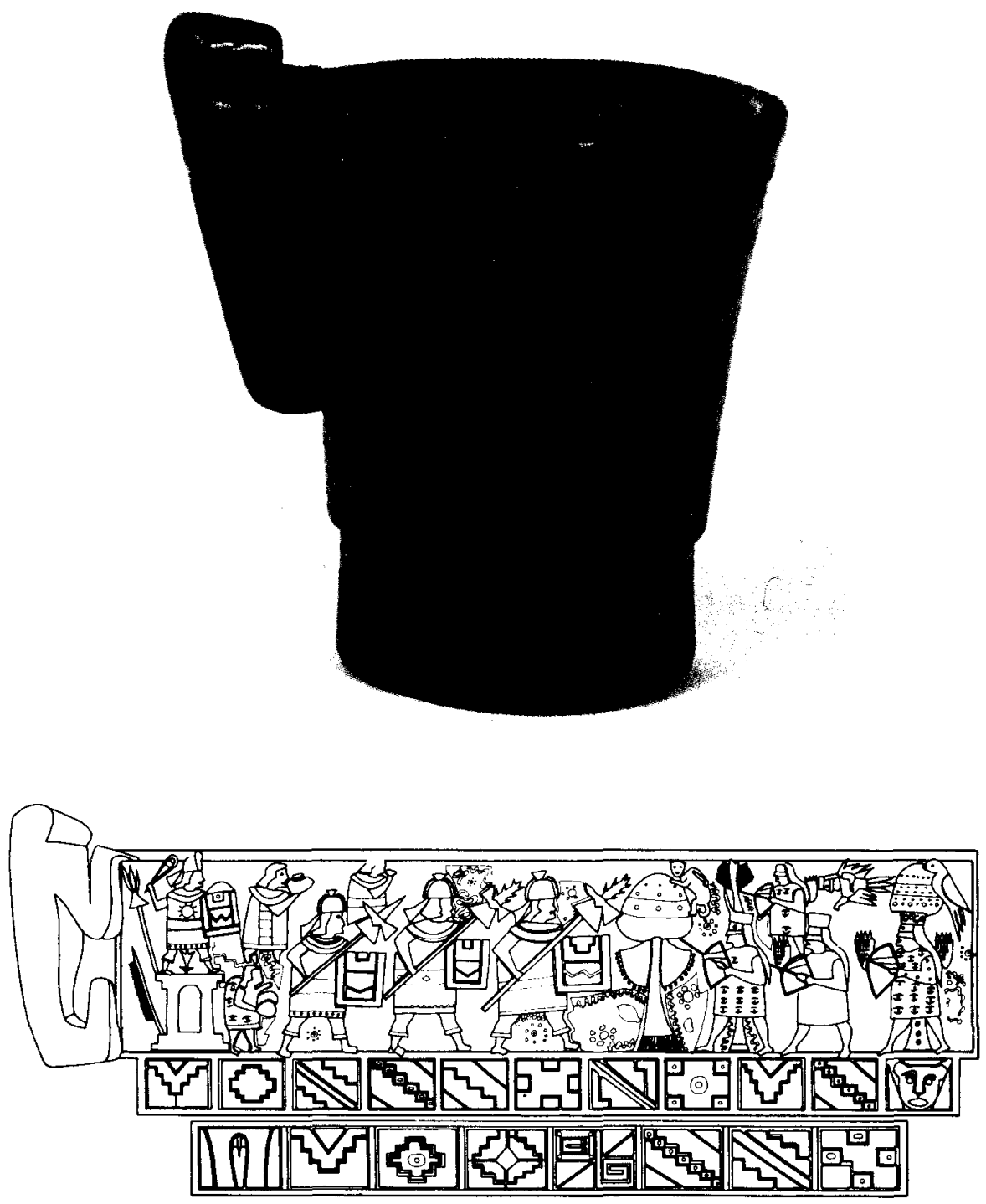

Fig. 9. Dero n. ${ }^{\circ}$ 7511. Desarrollo decorativo del Kero n. ${ }^{\circ} 7511$ M.A.M. 

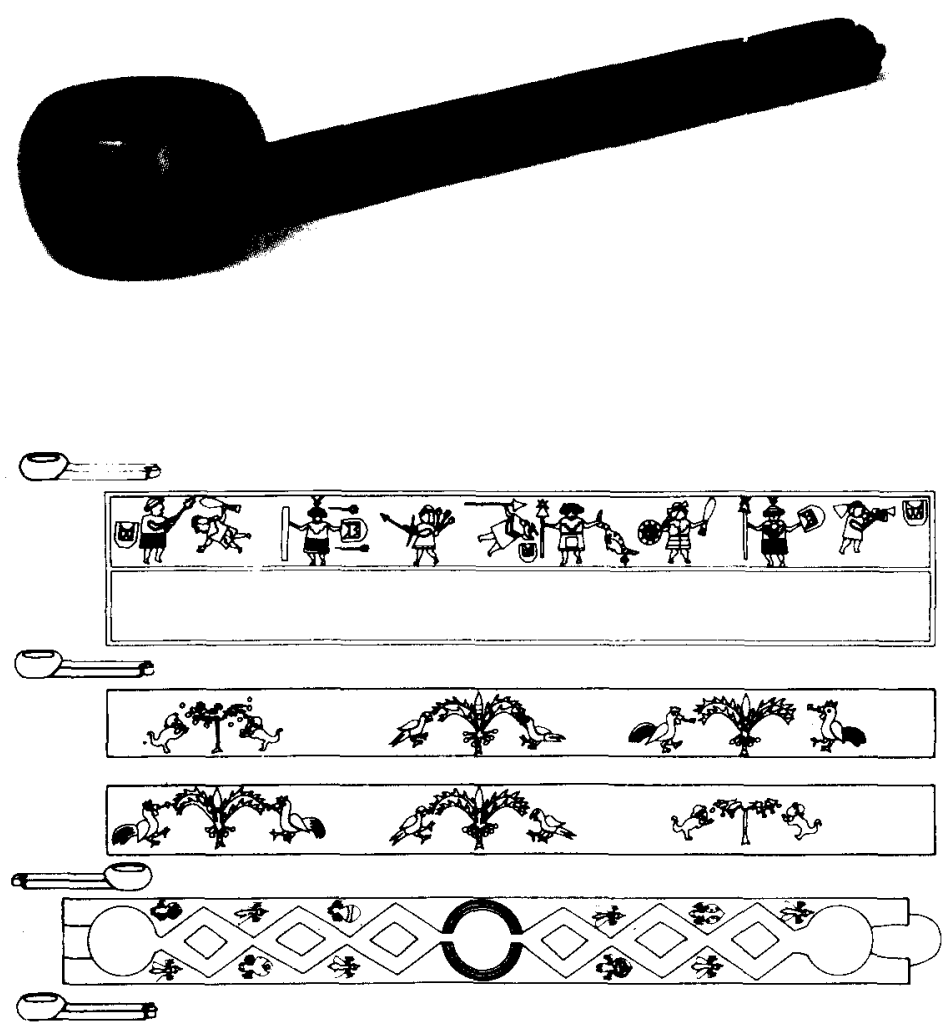

Fig. 10. Pajcha $n .^{\circ} 7570$. Desarrollo decorativo de la pajcha n. 7570 M.A.M. 

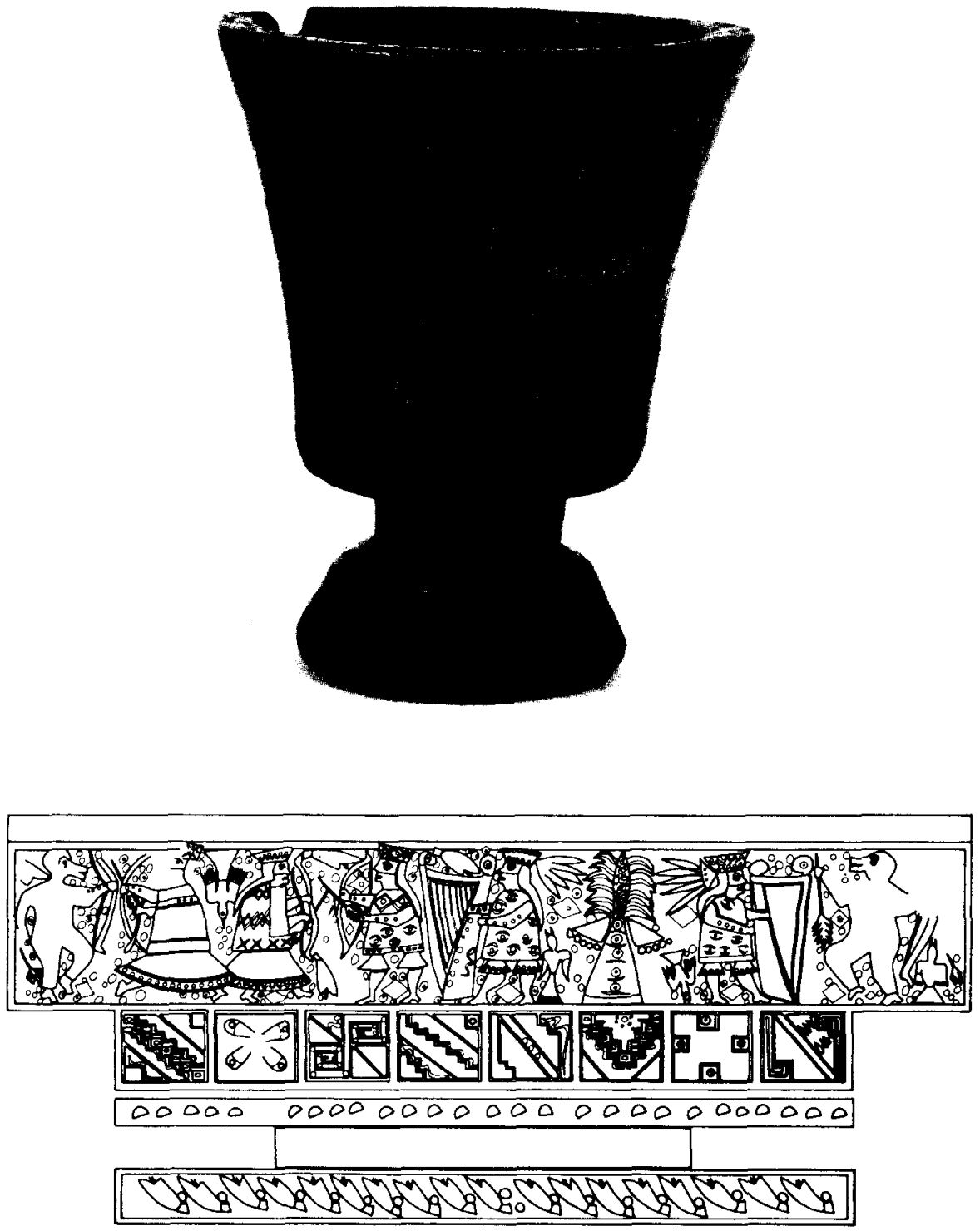

Fig. 11. Kero n. ${ }^{\circ} 7561$. Desarrollo decorativo del Kero n. 7561 M.A.M. 
dría también aludir a alguna ceremonia conmemorativa de algún pacto militar de los incas con las tribus selváticas ${ }^{30}$. La presencia de las arpas en este vaso pone de manifiesto el mestizaje instrumental habido tras la Conquista, dada la inexistencia de cordófonos con anterioridad a la misma.

Directamente relacionada con este tipo de conmemoraciones guerreras es la escena del kero $\mathrm{n} .^{\circ} 7531$ (fig. 12) donde seis personajes, ataviados con tocados de plumas y portando arcos, flechas y una bandera desfilan al son de una trompeta tocada por un hombre que pudiera ser negro. La aparición de los personajes no indígenas nos habla de la tardía fabricación del vaso y el episodio podría aludir, tras la Conquista, a un antiguo hecho histórico relacionado con las tribus selváticas.

Antes de finalizar queremos hacer una breve referencia a la compleja decoración de las restantes bandas que ornamentan los vasos a los que hemos hecho referencia. Dicha decoración está formada por motivos geométricos y florales que, en diversas combinaciones, acompañan a los motivos figurativos anteriormente aludidos. Entre los primeros los escalonamientos, rombos y círculos separan, cuando existe esta banda intermedia, la decoración figurativa contenida en las otras dos. Junto a dichos motivos es frecuente hallar formas cuadradas o rectangulares - denominadas tocapus - donde se encierran complejos motivos geométricos de posible contenido simbólico y difícil interpretación.

Por lo que respecta a los temas florales su frecuente estilización dificulta la identificación de las especies ${ }^{31}$, constituyendo motivos ornamentales de carácter simbólico vinculados al ritual y a la realeza. Estos elementos florales adquieren una gran simplificación decorativa en los keros n. 7551 y 7552 (figs. 13 y 14), acorde con los diseños geométricos y figurativos situados en las respectivas bandas superiores. En ellas, junto a motivos de tocapus, aparecen dos escenas de danza. La primera la ejecutan solo hombres, tal como solía ser usual en época inca, acompañados por una mujer que toca el tamboril. La segunda es una danza

30 Rostworowskide Díz Canseco, M. 1991, "La sociedad inca", Los Incas y el antiguo Perú. 3000 años de historia. Madrid, Sociedad Estatal, Quinto Centenario, pág. 391, establece cómo los incas sólo adquirieron poder tras sus repetidos triunfos militares. No obstante, en numerosos casos se trató de pacíficas anexiones territoriales realizadas sobre la base del ofrecimiento de la reciprocidad a los señores vecinos y de la unión entre ellos mediante lazos de parentesco, lo que éstos solian aceptar antes de ir a una guerra de trágicas consecuencias para el perdedor.

${ }_{31}$ VARGAS, F.C. 1981, "Plants motifs on Inca ceremonial vases from Perú», Botanical Journal of Linnean Society, págs. 313-325, London; YaCovLEF, E., y HeRRERA F.L. 1935, ‘El mundo vegetal de los antiguos peruanos", Revista del Museo Nacional, págs. 29-102, Lima 

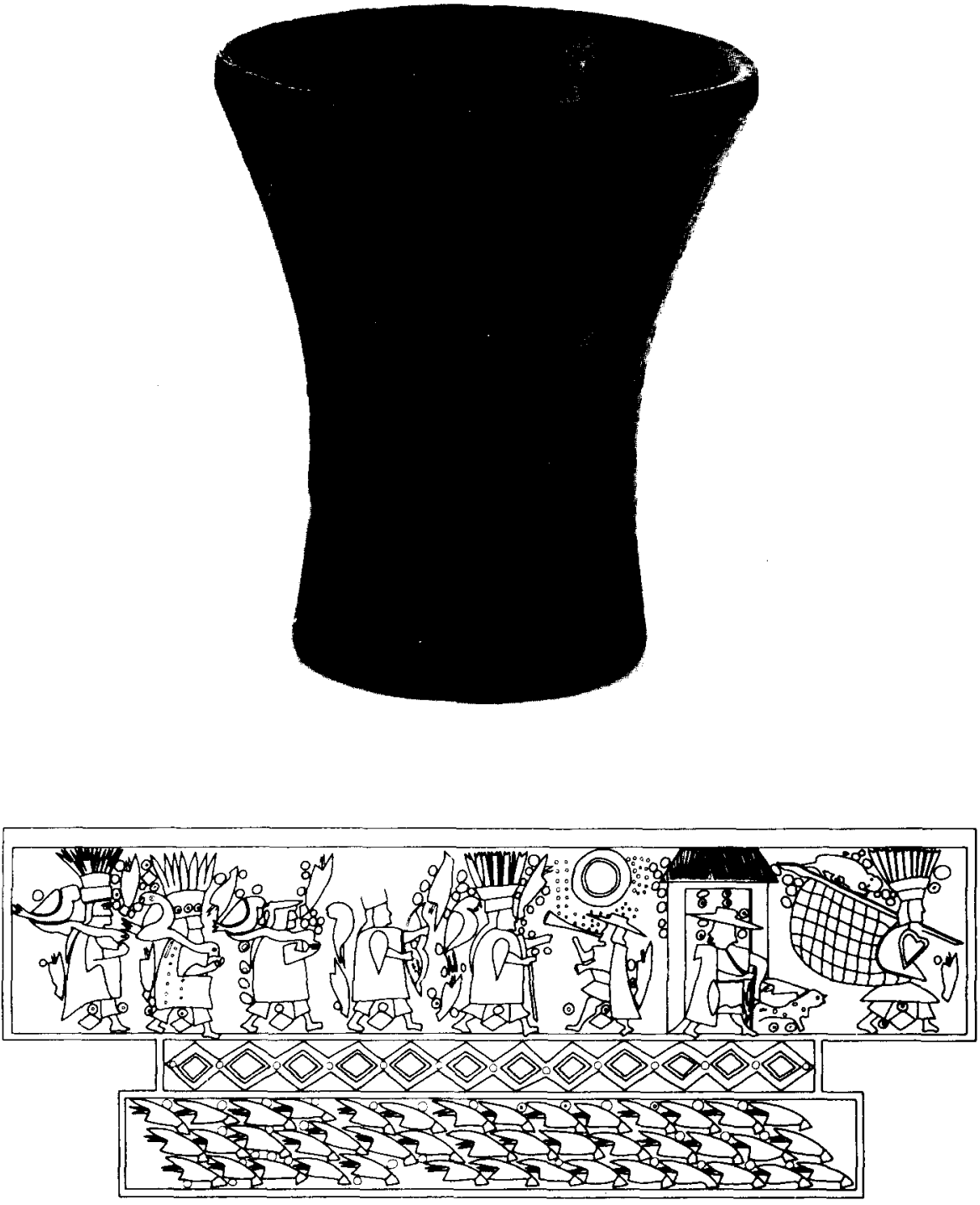

Fig. 12. Kero n. ${ }^{\circ} 7531$. Desarrollo decorativo del Kero n. 7531 M.A.M. 

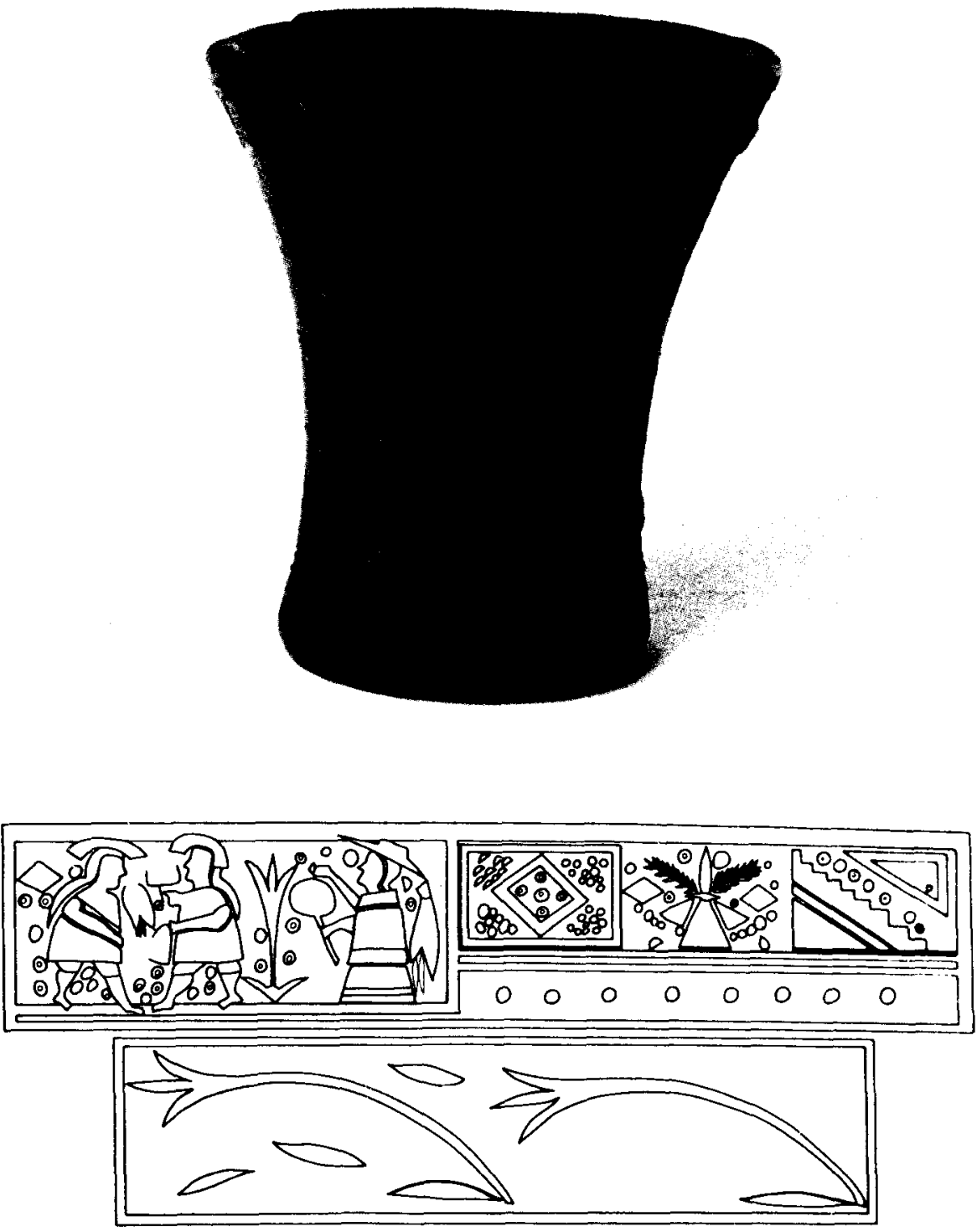

Fig. 13. Kero n. ${ }^{\circ} 7551$. Desarrollo decorativo del Kero n. ${ }^{\circ} 7551$ M.A.M. 
CRUZ MARTINEZ DE LA TORRE

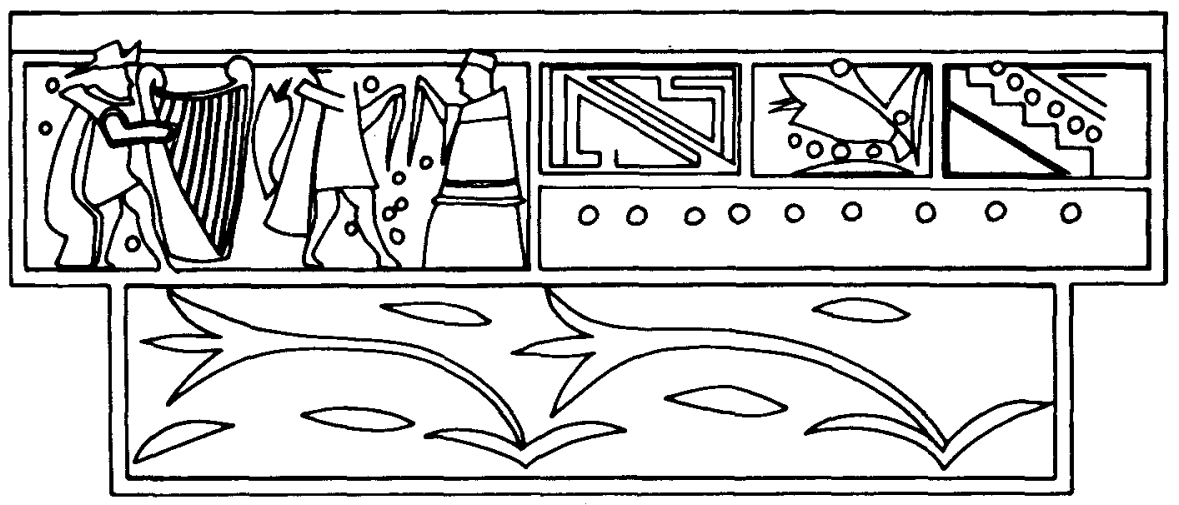

Fig. 14. Kero n. ${ }^{\circ}$ 7552. Desarrollo decorativo del Kero n. 7552 M.A.M.

34 
en la que participan una mujer, vestida a la manera indígena, y un hombre vestido a la europea y del que se omite la representación de la cabeza. Ambos llevan pañuelos en las manos, característica que ha perdurado hasta la actualidad en numerosos bailes del folklore andino, y danzan al son de un arpa ejecutada por un europeo. El tratamiento dado a las figuras - que suelen transgredir el marco decorativo adjudicado a la escena, omitiéndose incluso parte del cuerpo de una de ellas $-y$ la simplificación tanto de dicha escena como del resto de los motivos ornamentales, nos hablan de la ya tardía fabricación del vaso, anticipando la trayectoria decorativa que éstos seguirán a lo largo de los siglo XVII y XVIII. Pese a ello, ambas escenas constituyen un claro ejemplo del lugar que la música siguió teniendo en la vida de estas poblaciones en época virreinal, al tiempo que los soportes artísticos que las alojan, los keros, evocan su añoranza por el insigne pasado histórico en el que fueron creados. 
